\title{
Complex non-crystalline mineralogy protects soil carbon from temperature-dependent decay
}

Susan E. Crow ${ }^{1}$, CASEY MCGRath ${ }^{1}$, CAITLIN Hicks

Pries $^{2}$, Nhu NGUYeN ${ }^{1}$, Michelle LaZARO ${ }^{1}$, Christian GIARDINA $^{3}$, CREIGHTON LITTON ${ }^{1}$

${ }^{1}$ University of Hawaii Manoa, Honolulu, HI, USA (crows@hawaii.edu,mcgrathc@hawaii.edu, nhu.nguyen@hawaii.edu,mlazaro@hawaii.edu, litton@hawaii.edu)

${ }^{2}$ Dartmouth College, Hanover, NH, USA

(caitlin.pries@dartmouth.edu)

${ }^{3}$ USDA USFS - PSRS IPIF, Hilo, HI, USA

(christian.p.giardiana@usda.gov)

Mineral control on soil carbon (C) storage is well established, including the overarching role of poorly- or noncrystalline minerals (P-NCM) in $\mathrm{C}$ accumulation and stabilization. In volcanic ash-derived soils sampled from an undisturbed tropical montane wet forest along a $5.2^{\circ} \mathrm{C}$ mean annual temperature (MAT) gradient on the windward slopes of Mauna Kea on the Island of Hawaii, we observed variations in forms of $\mathrm{P}-\mathrm{NCM}$ and crystalline iron (Fe)-oxides that significantly explained $\mathrm{C}$ storage and turnover, while other variables including MAT did not. In a batch sorption experiment based on these soils, high concentrations of $\mathrm{P}$ NCM increased sorption of dissolved organic $\mathrm{C}$, and the degree of organo-Al complexation was positively related to preferential sorption of aromatics. High P-NCM concentrations decreased the amount of labile $\mathrm{C}$ respired, and a high index of organo-Al complexation decreased its apparent temperature sensitivity during incubation. Finally, recent studies show a strong, positive response of deep soil respiration to artificial warming. We installed a novel system of heaters and sensors to monitor real-time soil temperatures in a network across a hillslope of volcanic ash-derived soils at the Lyon Arboretum on the Island of Oahu. One year of warming did not affect soil $\mathrm{C}$ efflux on a hillslope past a depth of $40 \mathrm{~cm}$. High concentrations of P-NCM, high organo$\mathrm{Al}$ complexation index, and protection within concretions of crystalline Fe-oxides that collectively results in high soil $\mathrm{C}$ storage is likely to protect that soil $\mathrm{C}$ against loss under future anthropogenic stressors such as increased temperature. 